\title{
Effect of Shape of Armoring Fibers on Strength of Composite Materials
}

\section{Y.A.Vahterova ${ }^{1}$,Yan Naing Min²}

${ }^{1}$ Moscow Aviation Institute (National Research University), Volokolamskoeshosse, 4, 125993, Moscow, Russia ${ }^{2}$ Defense Services Academy (D.S.A), Department of MathematicsMandalay-Lashio highway street, PyinOo Lwin, Mandalay Division, Myanmar.

1'yana-vahterova@mail.ru

Article History: Received: 11 January 2021; Accepted: 27 February 2021; Published online: 5 April 2021

\begin{abstract}
In this work, experimental studies of the effect of fiber curvature on the strength and ultimate deformations of epoxy carbon plastic samples under loading are carried out. On the basis of the experimental studies carried out, the static characteristics of the composite layered material, which are promising for use in the structures under consideration, have been determined. Based on the test results, it was demonstrated that in the design calculations for the products under consideration, it is possible to use static characteristics, since an increase in the deformation rate of the material leads to an increase in strength and, therefore, the calculation results will provide an additional margin of safety.
\end{abstract} Keywords: Strength, deformation, loading, static tests.

\section{Introduction}

Currently, a large number of studies have been carried out to obtain and study the strength of composite materials[1-9]. A large amount of experimental data dedicated to the synthesis and exploration of heterophase composites were obtained[10-26]. However, well-known studies were carried out mainly for the case of quasistatic loading of materials. The effects of strain rate influence on the strength of composites with bent fibers have been studied to a much lesser extent, although they have also been considered [27-35]. Analytical and numerical models are proposed to take into account the effects of curved stacking and the effect of fiber curvature. Some applied models, in particular, are used in standard software packages for finite element modeling[36-47]. The buckling effects of fibers, even in the case of ideal straight-line packing, leads to a decrease in the compressive strength in relation to the ultimate tensile strength of the fiber composite by more than 1.5 times. The presence of bends in the fibers can reduce this characteristic even more.

\section{Study of the strength of composite materials}

Samples of the composite material were made on the basis of ED-20 epoxy resin with Torey T800 reinforcing fibers. The volumetric content of fibers was $60 \%$, the diameter of the fibers was $5 \mu \mathrm{m}$. Samples of three types were considered: 1) a quasi-homogeneous layered composite with a unidirectional reinforcement scheme, 2) a unidirectional composite with a wavelike layered structure, and 3) a pure matrix.

Mechanical tests were carried out on a universal electrical installation Instron 5969 (50kN) and Instron 5982 $(100 \mathrm{kN})(\mathrm{UK})$ with Bluehill 3 software. Compression tests were carried out. Test speed was $1 \mathrm{~mm} / \mathrm{min}$.

Photos of the samples after testing are shown in Figure 1. According to the test results, characteristic loaddisplacement and stress-strain diagrams were obtained, Fig. 1a for straight installation, Fig. 1b for wavy styling. 

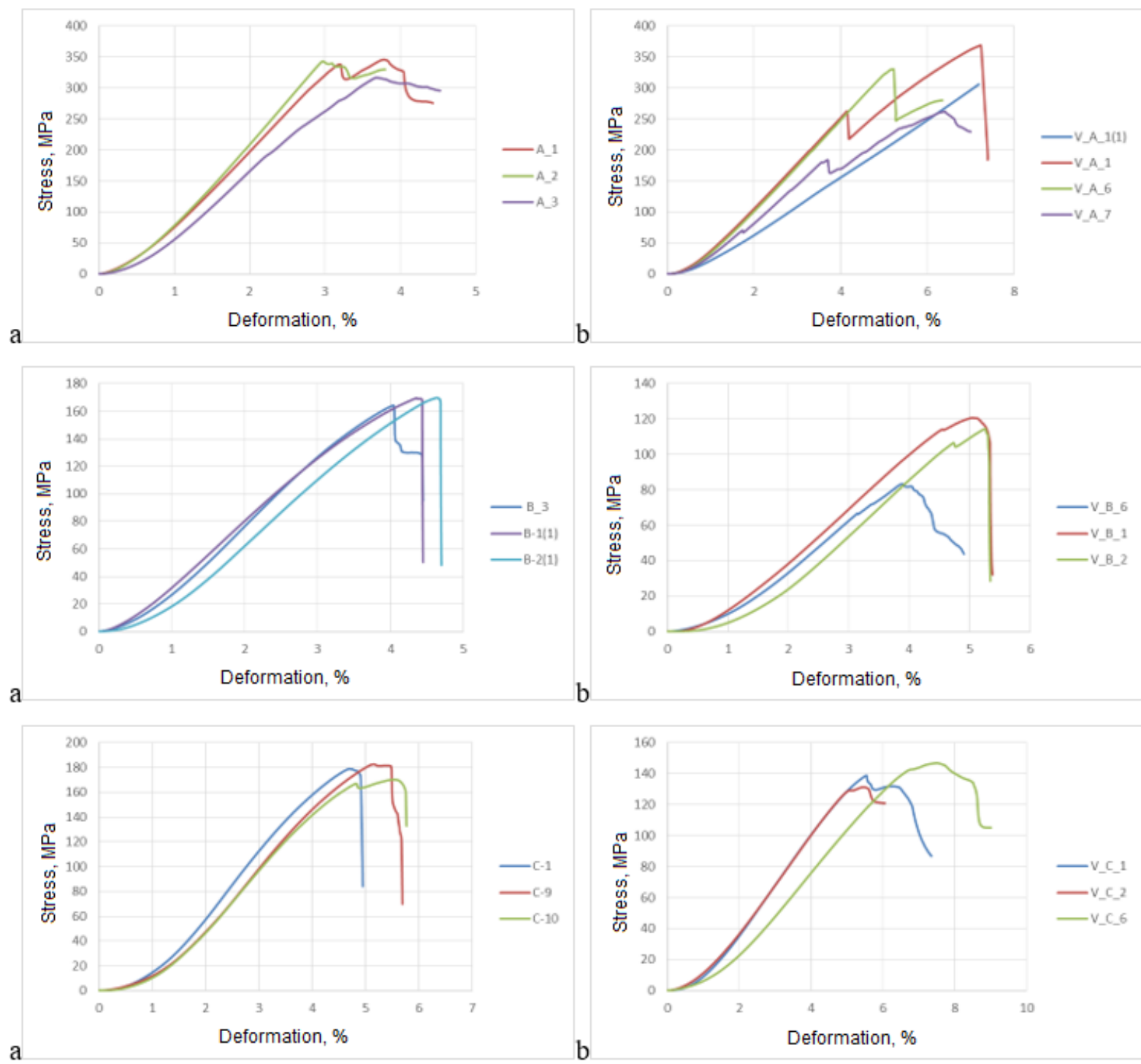

Figure: 1. Stress-strain diagrams obtained during static compression test of specimens with straight (a) and wavy packing (b).

For each batch, the resulting diagram was obtained as a result of averaging the experimental data for three samples of the same type (Figure 2). During the tests, the maximum load, ultimate strength and ultimate deformation were determined for each specimen. The results of static tests are presented in the Figure 2. 


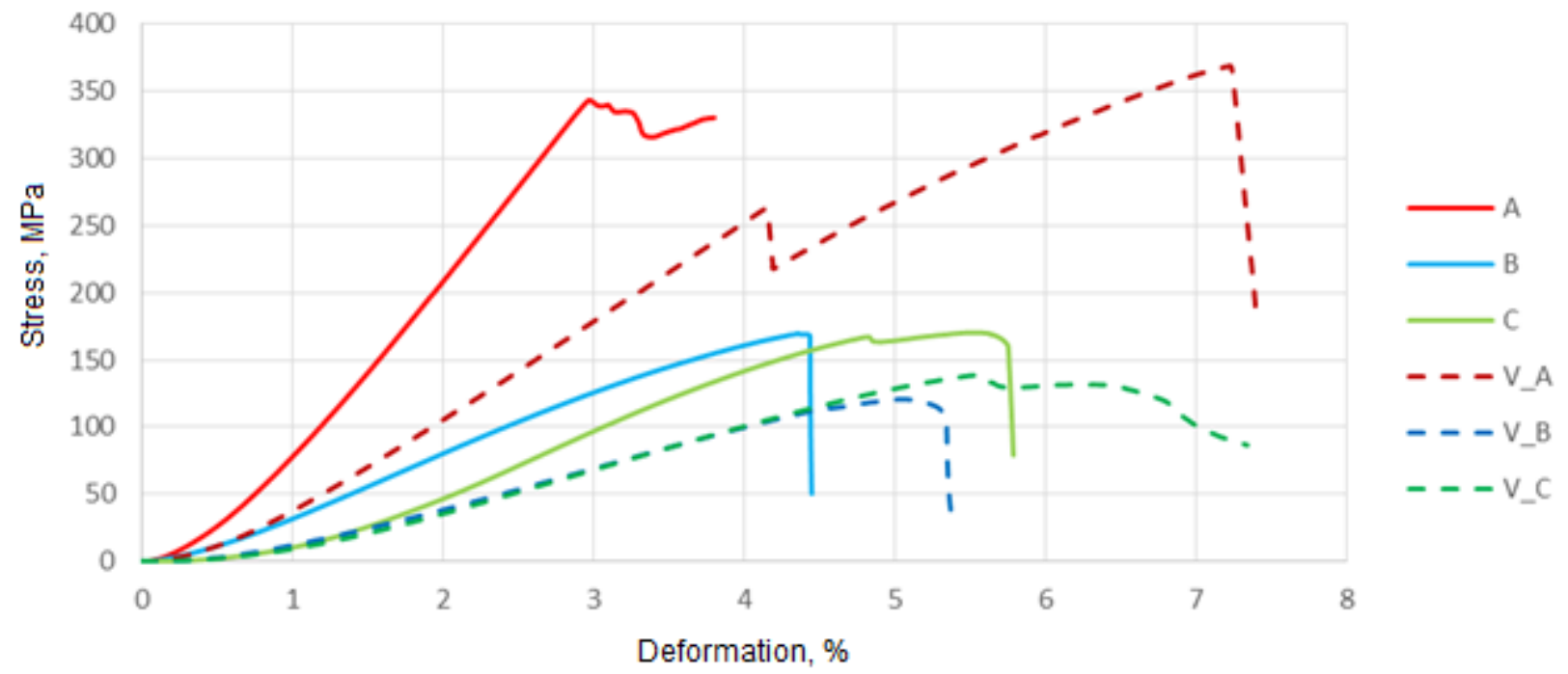

Figure: 2. The resulting stress-strain diagram obtained in a static compression test of specimens with straight (solid lines) and wavy packing (dashed lines).

The strength of the matrix was also tested. The tests were carried out on an Instron 5969 installation, with the maximum possible speed for this installation equal to $600 \mathrm{~mm} / \mathrm{min}$. The stress-strain graph is shown in Figure 3.

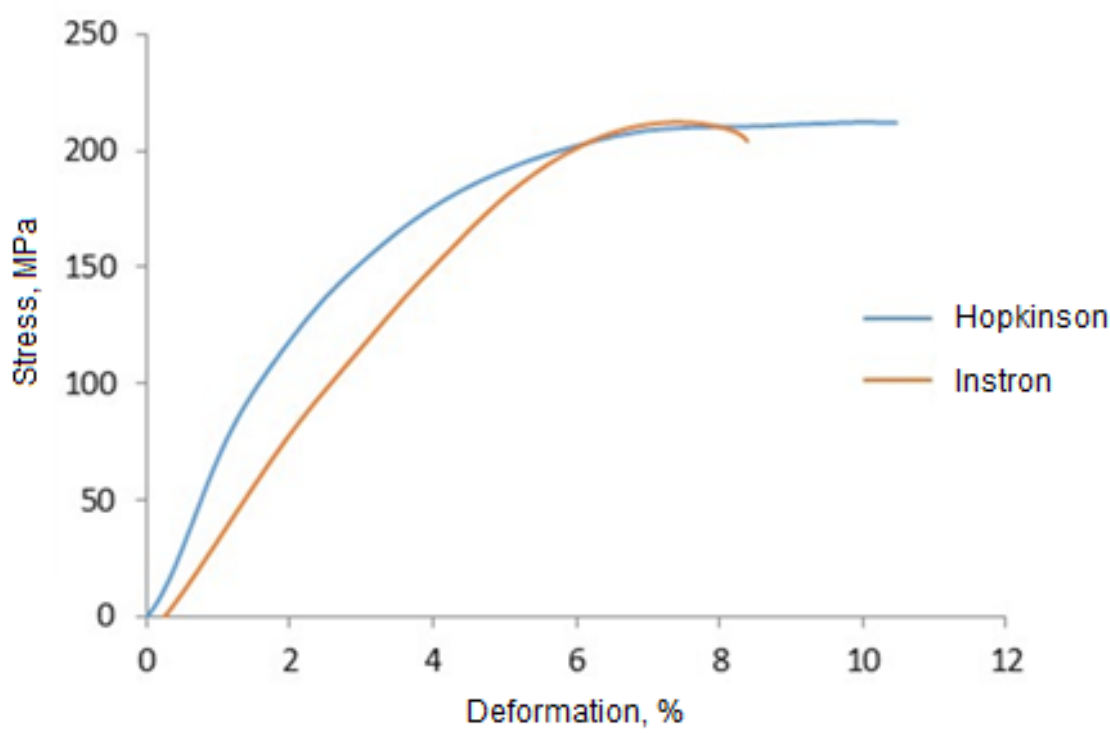

Figure: 3. The resulting stress-strain diagram obtained during static and dynamic compression tests of specimens made of epoxy resin ED 20.

From static tests it can be seen that the ultimate strength in unidirectional laying is higher than in wavy laying (in the direction A-5\%, in the direction B-32\%, in the direction C-23\%), and the ultimate deformations in unidirectional laying are higher than in wavy styling.

From static tests it can be seen that the ultimate strength in direction A for unidirectional laying (335 MPa) is higher than for wavy $(318 \mathrm{MPa})$, in direction $\mathrm{B}$ for unidirectional laying (168 MPa) it is higher than for wavy (114 MPa), in direction $\mathrm{C}$ for unidirectional laying (177 MPa) is higher than for wavy (137 MPa).

It is also seen from static tests that the ultimate deformations in the A direction for unidirectional laying $(3,47 \%)$ are lower than for wavy $(6,78 \%)$, in the B direction for unidirectional laying $(4,34 \%)$ is lower than for wavy $(5,16 \%)$, in the $\mathrm{C}$ direction for unidirectional styling $(5,12 \%)$ is lower than for wavy $(6,04 \%)$.

\section{Conclusions}

Static tests of the strength of unidirectional CFRP specimens with rectilinear and wavy structure have been carried out. For the first time, a detailed study of the effect of fiber curvature on the properties of CFRP under 
static deformation has been carried out. As a result of static tests, it was found that the ultimate strength in unidirectional laying is higher than in wavy laying. The effect of increasing the ultimate deformations of specimens with bent fibers is established, which was noted earlier for the case of tensile tests.

\section{Acknowledgements}

This work was carried out with the financial support of RFBR, project No. 20-38-90043.

\section{References}

1. Rabinskiy, L.N., Tushavina, O.V., Formalev, V.F. Mathematical modeling of heat and mass transfer in shock layer on dimmed bodies at aerodynamic heating of aircraft// Asia Life Sciences, 2019, (2), p. 897-911.

2. Formalev, V.F., Kartashov, É.M., Kolesnik, S.A. On the Dynamics of Motion and Reflection of Temperature Solitons in Wave Heat Transfer in Limited Regions // Journal of Engineering Physics and Thermophysics, 2020, 93(1), p. 10-15.

3. Formalev, V.F., Bulychev, N.A., Kuznetsova, E.L., Kolesnik, S.A. The Thermal State of a Packet of Cooled Microrocket Gas-Dynamic Lasers // Technical Physics Letters, 2020, 46(3), p. 245-248.

4. Antufev, B.A., Egorova, O.V., Rabinskiy, L.N. Quasi-static stability of a ribbed shell interacting with moving load// INCAS Bulletin, 2019, 11, p. 33-39.

5. Bodryshev, V.V., Babaytsev, A.V., Rabinskiy, L.N. Investigation of processes of deformation of plastic materials with the help of digital image processing// PeriodicoTcheQuimica, 2019, 16(33), p. 865-876.

6. Astapov, A.N., Kuznetsova, E.L., Rabinskiy, L.N. Operating capacity of anti-oxidizing coating in hypersonic flows of air plasma//Surface Review and Letters, 2019, 26(2), 1850145 p.

7. Rabinskiy, L.N., Tushavina, O.V., Starovoitov, E.I. Study of thermal effects of electromagnetic radiation on the environment from space rocket activity // INCAS Bulletin, 2020, 12(Special Issue), p. 141-148.

8. Babaytsev, A.V., Orekhov, A.A., Rabinskiy, L.N. Properties and microstructure of AlSi10Mg samples obtained by selective laser melting// Nanoscience and Technology: An International Journal, 2020, 11(3), p. 213-222.

9. Egorova, O.V., Kyaw, Y.K. Solution of inverse non-stationary boundary value problems of diffraction of plane pressure wave on convex surfaces based on analytical solution//Journal of Applied Engineering Science, 2020, 18(4), p. 676-680.

10. Bulychev N. A., Kuznetsova E.L., Bodryshev V. V.Rabinskiy L.N. Nanotechnological aspects of temperature-dependent decomposition of polymer solutions, Nanoscience and Technology: An International Journal, 2018, Vol. 9 (2), p.91-97.

11. Bulychev, N.A., Rabinskiy, L.N. Ceramic nanostructures obtained by acoustoplasma technique//Nanoscience and Technology: An International Journal, 2019, 10(3), p. 279-286.

12. O.A. Butusova. Surface Modification of Titanium Dioxide Microparticles Under Ultrasonic Treatment, International Journal of Pharmaceutical Research, 2020, Vol. 12, I. 4, pp. 2292-2296.

13. B.A. Garibyan. Enhancement of Mechanical Properties of Inorganic Glass under Ultrasonic Treatment, International Journal of Pharmaceutical Research, 2020, Vol. 12, Supplementary Issue 2, pp. 18291832.

14. O.A. Butusova. Stabilization of Carbon Microparticles by High-Molecular Surfactants, International Journal of Pharmaceutical Research, 2020, Vol. 12, Supplementary Issue 2, pp. 1147-1151.

15. A.N. Tarasova. Vibration-based Method for Mechanochemical Coating Metallic Surfaces, International Journal of Pharmaceutical Research, 2020, Vol. 12, Supplementary Issue 2, pp. 1160-1168.

16. B.A. Garibyan. Mechanical Properties of Electroconductive Ceramics, International Journal of Pharmaceutical Research, 2020, Vol. 12, Supplementary Issue 2, pp. 1825-1828.

17. O.A. Butusova. Vinyl Ether Copolymers as Stabilizers of Carbon Black Suspensions, International Journal of Pharmaceutical Research, 2020, Vol. 12, Supplementary Issue 2, pp. 1152-1155.

18. O.A. Butusova. Adsorption Behaviour of Ethylhydroxyethyl Cellulose on the Surface of Microparticles of Titanium and Ferrous Oxides, International Journal of Pharmaceutical Research, 2020, Vol. 12, Supplementary Issue 2, pp. 1156-1159.

19. B.A. Garibyan. Modelling of Technical Parameters of Discharge Reactor for Polymer Treatment, International Journal of Pharmaceutical Research, 2020, Vol. 12, Supplementary Issue 2, pp. 18331837. 
20. M.O. Kaptakov. Effect of Ultrasonic Treatment on Stability of TiO2 Aqueous Dispersions in Presence of Water-Soluble Polymers, International Journal of Pharmaceutical Research, 2020, Vol. 12, Supplementary Issue 2, pp. 1821-1824.

21. M.O. Kaptakov. Catalytic Desulfuration of Oil Products under Ultrasonic Treatment, International Journal of Pharmaceutical Research, 2020, Vol. 12, Supplementary Issue 2, pp. 1838-1843.

22. M.O. Kaptakov. Enhancement of Quality of Oil Products under Ultrasonic Treatment, International Journal of Pharmaceutical Research, 2020, Vol. 12, Supplementary Issue 2, pp. 1851-1855.

23. Yu.V. Ioni. Synthesis of Metal Oxide Nanoparticles and Formation of Nanostructured Layers on Surfaces under Ultrasonic Vibrations, International Journal of Pharmaceutical Research, 2020, Vol. 12, Issue 4, pp. 3432-3435.

24. Yu.V. Ioni, A. Ethiraj. Study of Microparticles Surface Modification by Electrokinetic Potential Measuring, International Journal of Pharmaceutical Research, 2020, Vol. 12, Issue 4, pp. 3436-3439.

25. A.N. Tarasova. Effect of Reagent Concentrations on Equilibria in Water-Soluble Complexes, International Journal of Pharmaceutical Research, 2020, Vol. 12, Supplementary Issue 2, pp. 11691172.

26. A.N. Tarasova. Effect of Vibration on Physical Properties of Polymeric Latexes, International Journal of Pharmaceutical Research, 2020, Vol. 12, Supplementary Issue 2, pp. 1173-1180.

27. Yu.V. Ioni. Effect of Ultrasonic Treatment on Properties of Aqueous Dispersions of Inorganic and Organic Particles in Presence of Water-Soluble Polymers, International Journal of Pharmaceutical Research, 2020, Vol. 12, Issue 4, pp. 3440-3442.

28. N.A. Bulychev, A.V. Ivanov. Nanostructure of Organic-Inorganic Composite Materials Based on Polymer Hydrogels, International Journal of Nanotechnology, 2019, Vol. 16, Nos. 6/7/8/9/10, pp. 344 355.

29. N.A. Bulychev, A.V. Ivanov. Study of Nanostructure of Polymer Adsorption Layers on the Particles Surface of Titanium Dioxide, International Journal of Nanotechnology, 2019, Vol. 16, Nos. 6/7/8/9/10, pp. $356-365$.

30. Yu.V. Ioni, A. Ethiraj. New Tailor-Made Polymer Stabilizers for Aqueous Dispersions of Hydrophobic Carbon Nanoparticles, International Journal of Pharmaceutical Research, 2020, Vol. 12, Issue 4, pp. 3443-3446.

31. Yu.V. Ioni. Nanoparticles of noble metals on the surface of graphene flakes, PeriodicoTcheQuimica, 2020, Vol. 17, No. 36, pp. 1199-1211.

32. N.A. Bulychev, M.A. Kazaryan. Optical Properties of Zinc Oxide Nanoparticles Synthesized in Plasma Discharge in Liquid under Ultrasonic Cavitation, Proceedings of SPIE, 2019, Vol. 11322, article number 1132219.

33. N.A. Bulychev, A.V. Ivanov. Effect of vibration on structure and properties of polymeric membranes, International Journal of Nanotechnology, 2019, Vol. 16, Nos. 6/7/8/9/10, pp. $334-343$.

34. Anikin V.A., Vyshinsky V.V., Pashkov O.A., et al. Using the maximum pressure principle for verification of calculation of stationary subsonic flow. Herald of the Bauman Moscow State Technical University, Series Mechanical Engineering, 2019, no. 6, pp. 4-16.

35. Bulychev, N.A., Rabinskiy, L.N., Tushavina, O.V. Effect of intense mechanical vibration of ultrasonic frequency on thermal unstable low-temperature plasma// Nanoscience and Technology: An International Journal, 2020, 11(1), p. 15-21.

36. Rabinskiy, L.N., Sitnikov, S.A. Development of technologies for obtaining composite material based on silicone binder for its further use in space electric rocket engines// PeriodicoTcheQuimica, 2018, 15(Special Issue 1), p. 390-395.

37. Formalev, V.F., Kolesnik, S.A., Selin, I.A. Local non-equilibrium heat transfer in an anisotropic halfspace affected by a non-steady state point heat source // Herald of the Bauman Moscow State Technical University, Series Natural Sciences. 2018. 80(5), p. 99-111.

38. Kolesnik, S.A., Bulychev, N.A., Rabinskiy, L.N., Kazaryan, M.A. Mathematical modeling and experimental studies of thermal protection of composite materials under high-intensity effects of laser radiation// Proceedings of SPIE - The International Society for Optical Engineering. 2019. 11322, article number 113221R.

39. Kuznetsova, E.L., Rabinskiy, L.N. Heat transfer in nonlinear anisotropic growing bodies based on analytical solution // Asia Life Sciences, 2019, (2), p. 837-846.

40. Kuznetsova, E.L., Rabinskiy, L.N. Numerical modeling and software for determining the static and linkage parameters of growing bodies in the process of non-stationary additive heat and mass transfer//PeriodicoTcheQuimica, 2019, 16(33), p. 472-479.

41. Kuznetsova, E.L., Rabinskiy, L.N. Linearization of radiant heat fluxes in the mathematical modeling of growing bodies by the action of high temperatures in additive manufacturing //Asia Life Sciences, 2019, (2), p. 943-954. 
42. Babaytsev, A.V., Kuznetsova, E.L., Rabinskiy, L.N., Tushavina, O.V. Investigation of permanent strains in nanomodified composites after molding at elevated temperatures// PeriodicoTcheQuimica, 2020, 17(34), p. 1055-1067.

43. Zaripov R.N., Murakaev I.M., Novikov S.V., Ryapukhin A.V. Corporate Structure for Innovative Enterprises, Russian Engineering Research, 2020,Vol. 40, I. 2, pp. 137-139.

44. BurovaA.Yu.,Ryapukhin A.V.,Muntyan A.R. Reduced hardware costs with software and hardware implementation of digital methods multistage discrete Fourier transform on programmable logic devices, Amazonia Investiga, 2020, Vol. 9, I. 27, pp. 227-233.

45. Rabinsky, L.N., Kuznetsova, E.L. Simulation of residual thermal stresses in high-porous fibrous silicon nitride ceramics // Powder Metallurgy and Metal Ceramics, 2019, 57(11-12), p. 663-669.

46. Rabinskiy, L.N. Non-stationary problem of the plane oblique pressure wave diffraction on thin shell in the shape of parabolic cylinder// PeriodicoTcheQuimica, 2019, 16(32), p. 328-337.

47. Dobryanskiy, V.N., Rabinskiy, L.N., Tushavina, O.V. Experimental finding of fracture toughness characteristics and theoretical modeling of crack propagation processes in carbon fiber samples under conditions of additive production// PeriodicoTcheQuimica, 2019, 16(33), p. 325-336. 